\title{
PENGEMBANGAN PENANGKARAN BENIH TEBU (SACCHARUM OFFICINARUM L.) METODE SINGGLE BUD PLANTING UNTUK MENUNJANG SWASEMBADA GULA NASIONAL
}

\author{
Endang Suhesti1 ${ }^{*}$, Puryantoro ${ }^{2)}$, Yasmini Suryaningsih ${ }^{3)}$ \\ Fakultas Pertanian, Universitas Abdurachman Saleh Situbondo \\ *Email Korespondensi : hesty_soehardjo@yahoo.co.id
}

\begin{abstract}
Abstrak
Penelitian ini dilaksanakan di Kampung Locancang, Desa Paowan, kecamatan Panarukan, Kabupaten Situbondo, Jawa Timur. Tujuannya adalah untuk meningkatkan ketersediaan benih tebu unggul bersertifikat bagi petani melalui perluasan KBD di setiap Wilayah Kerja Pabrik Gula. Bahan tanam diperoleh dari Kebun Percobaan (KP) P3GI Pasuruan. Varietas yang ditanam adalah Varietas tebu unggul (PS 862). Pendekatan taksasi produksi mata tunas per hektar menggunakan persamaan regresi eksponensial sehingga akan diketahui kebutuhan benih berdasarkan luasan areal tanam dan dapat dibuat rekomendasi jumlah dan sebaran penangkar benih di wilayah Pabrik Gula di Kabupaten Situbondo. Taksasi produksi jumlah mata per hektar dapat dilakukan sebelum panen (umur tanaman 5 BST) dengan menggunakan regresi eksponensial. Metode ini diterapkan untuk system tanam bagal. Hasil penelitian menghasilkan jumlah batang rata-rata per hektar adalah 8.49 batang/m sehingga produksi mata tunas per hektar yang ditanam dengan metode bagal adalah 681.888,6 mata per ha. Jumlah ini dapat digunakan untuk benih tanam tebu KTG seluas 7.01 hektar. Untuk luas wilayah tanam PG. Wringin Anom adalah 924,0 ha membutuhkan benih untuk KTG sebanyak 88.704.000 mata tunas. Dengan metode bagal dapat dipenuhi dari luas lahan KBD 130,09 ha. Sementara untuk Wilayah Kerja PG. Pandji dengan luas tanam 124 ha membutuhkan benih sebanyak 11.956 .060 mata tunas, dapat dipenuhi dari 17,53 ha lahan KBD, Dengan metode SBP kebutuhan benih dapat dipenuhi dari lahan KBD seluas 39,32 ha dengan dengan jumlah benih 1.108.800 mata. Untuk PG. kebutuhan benih tersebut dapat dipenuhi dari lahan KBD seluas 5.3 ha dengan jumlah benih yang ditanam sebanyak 149.451 mata tunas.
\end{abstract}

Kata Kunci : benih unggul, penangkaran benih, single bud planting

\begin{abstract}
This research was carried out in Locancang Village, Paowan Village, Panarukan Subdistrict, Situbondo Regency, East Java. The aim is to increase the amount of sugar cane seeds higher for farmers through KBD in each Sugar Mill Working Area. The planting material was obtained from the Pasuruan P3GI Experimental Garden (KP). The varieties planted are superior sugar cane varieties (PS 862). Related to the production of bud buds per hectare, the exponential regression equation is used so that the seed needs are understood based on the area of the planting area and an estimation of the number and distribution of seed breeders in the Sugar Factory area in Situbondo Regency. The production of the number of eyes per hectare can be carried out before harvest (plant age 5 BST) using exponential regression. This method is applied to mule planting systems. The results of the study resulted in an average number of stems per hectare of 8.49 stems / $m$ making the production of buds per hectare planted by the mule method 681.888.6 eyes per ha. This amount can be used for planting KTG sugar cane seeds covering an area of 7.01 hectares. For the planting area of PG. Wringin Anom is 924.0 ha needing seeds for KTG 88,704,000 buds. With the mule method, it can support 130,000 ha of KBD's land area. While for the PG Working Area. Pandji with 124 ha of planting area requires 11,956,060 seeds of buds, can support from 17.53 ha of KBD land, With the SBP method the need for seeds can increase from 39.32 ha of KBD land with a
\end{abstract}


number of seeds of 1,108,800 eyes. For PG. The need for seeds can be expanded from the WBD area of 5.3 ha with the number of seeds planted of 149,451 buds.

Key Word : superior seeds, breeding seeds, single bud planting

\section{PENDAHULUAN}

Target swasenbada gula tidak dapat dilepaskan dari kontribusi daerah-daerah penyumbang gula di Indonesia. Jawa Timur sebagai salah satu penyumbang gula terbesar $(49,14 \%)$ peranannya dibutuhkan untuk memenuhi kebutuhan penyediaan produksi gula (Pertanian, 2016). Kabupaten Situbondo sebagai salah satu kabupaten penghasil tebu/gula di Jawa Timur diharapkan eksistensinya untuk mendukung swasembada gula nasional. Salah satu kendala yang dihadapi di daerah pengembangan tebu antara lain adalah ketersediaan benih yang tidak memadai, baik kualitas maupun kuantitas. Program bongkar ratun yang dicanangkan Kementerian Pertanian mengakibatkan semakin tingginya permintaann benih tebu. Dalam hal ini diperlukan teknik perbanyakan benih tebu secara efektif dan efisien dalam upaya memenuhi kebutuhan benih pada Kebun Tebu Giling.

Salah satu upaya yang dapat dilakukan adalah memperbaiki kultur teknis budidaya tanaman tebu yaitu dengan menyediakan bibit tebu unggul bersertifikat tepat waktu, secara masal dalam waktu singkat dapat menyediakan bibit yang homogen baik masak awal, tengah dan lambat. Di lain pihak, difusi hasil riset bibit tebu unggul ke petani harus optimal.

Pengadaan benih pada tanaman tebu yang akan dipanen secara besar-besaran dalam waktu yang cepat akan sulit dicapai melalui teknik tradisional. Produksi benih konvensional dilakukan secara berjenjang dan memerlukan waktu yang cukup lama. Oleh karena itu perlu dicari suatu cara untuk mendapatkan benih yang sehat dengan proses perbanyakan yang cepat. Teknologi tanam tunas tunggal atau dikenal dengan Single Bud Planting (SBP) merupakan alternatif untuk mendapatkan benih sehat secara cepat. Penelitian ini akan memaparkan pengembangan industri bibit tebu unggul guna mewujudkan swasembada gula nasional.

\section{METODE PENELITIAN}

Penelitian ini dilaksanakan di Kampung Locancang, Desa Paowan, kecamatan Panarukan, Kabupaten Situbondo, Jawa Timur. Tujuannya adalah untuk meningkatkan ketersediaan benih tebu unggul bersertifikat bagi petani melalui perluasan KBD di setiap Wilayah Kerja Pabrik Gula. Bahan tanam diperoleh dari Kebun Percobaan (KP) P3GI Pasuruan. Varietas yang ditanam adalah Varietas tebu unggul (PS 862). Pendekatan taksasi produksi mata tunas per hektar menggunakan persamaan regresi eksponensial sehingga akan diketahui kebutuhan benih berdasarkan luasan areal tanam dan dapat dibuat rekomendasi jumlah dan sebaran penangkar benih di wilayah Pabrik Gula di Kabupaten Situbondo.

Data dalam penelitian ini digunakan untuk mengetahui proyeksi angka luas lahan tanam penangkaran benih untuk memenuhi kebutuhan Kebun Tebu Giling (KTG) di Wilayah Kerja PG. Wringin Anom, dan PG. Panji Situbondo.

\section{HASIL DAN PEMBAHASAN \\ Pengembangan Benih Tebu Unggul}

Pabrik Gula Wringin Anom berada di Kecamatan Panarukan dengan luas areal tanam tebu 924,0 ha dengan produksi sebesar 11.088,00 ton. Desa Wringin Anom merupakan salah satu di antara 6 desa yang ada di Kecamatan Panarukan, yang 
merupakan lokasi berdirinya Pabrik Gula Wringin Anom. Sekitar 80 \% tebu yang digiling di Pabrik Gula Wringin Anom ditanam di Desa Wringin agar tercipta efisiensi produksi, sedangkan $20 \%$ tebu yang yang dijadikan bahan baku berasal dari Desa di dekat Wringin seperti Peleyan dan Duwet.

Produksi gula pada PG. Wringin Anom Kabupaten Situbondo cenderung berfluktuasi. Hal ini terutama disebabkan oleh kerusakan alat di pabrik dan keterlambatan pasokan bahan baku tebu karena faktor lain seperti cuaca sehingga memperlambat proses produksi.

Pabrik Gula Pandji PT. Perkebunan Nusantara XI (Persero) merupakan salah satu perusahaan BUMN (Badan Usaha Milik Negeri) yang bergerak di bidang agroindustri yang mengolah tanaman tebu sebagai bahan utama untuk menghasilkan gula dan tetes. Perusahaan ini terletak di Jalan Situbondo-Banyuwangi, tepatnya di Desa Pandji, Kelurahan Mimbaan - Kabupaten Situbondo. Proses produksi gula kristal putih (GKP) pada Pabrik Gula Pandji PT. Perkebunan Nusantara XI melalui beberapa tahap yang diantaranya adalah proses tebang angkut, pemerahan nira, pemurnian, penguapan, kristalisasi, pengayakan, pendinginan dan pengemasan. PG Pandji memiliki luas areal tanam tebu 124,0 ha dan mampu memproduksi tebu sebesar 1.488 ton. Dalam upaya peningkatan produktivitasnya, PG Pandji antara lain melakukan optimalisasi masa tanaman dan penataan varietas.

Kedua perusahaan ini merupakan salah satu perusahaan BUMN (Badan Usaha Milik Negara) yang bergerak di bidang agroindustry yang mengolah tanaman tebu sebagai bahan utama untuk menghasilkan gula. Bahan baku tebu merupakan tanaman semusim yang hanya berproduksi satu tahun sekali dan perusahaan harus melakukan kegiatan produksi secara kontinyu sehingga perusahaan harus menjaga ketersediaan bahan baku yaitu tebu.

Penanaman tebu dalam luas optimal di lahan sawah maupun lahan kering akan memberikan peningkatan efisiensi dalam proses produksinya. Terlebih jika penanaman tebu dilakukan dengan penggunaan input yang tepat maka akan berpengaruh positif pada peningkatan produktivitas. Di wilayah Jawa, produsen benih tebu hanya mampu memasok kebutuhan benih sebanyak 40\% (Ismail, N.M., 2005), 60\% sisanya menggunakan tebu local yang produktivitasnya rendah. Pengembangan penangkar benih tebu unggul dengan metode Singgle Bud Planting akan sangat bermanfaat bagi peningkatan produktivitas tebu di kalangan petani.

\section{Taksasi Hasil Benih Tebu}

Pendekatan taksasi produksi mata tunas per ha sebelum tebang dapat dilakukan dengan analisa regresi eksponensial menggunakan variabel bebas jumlah batang per meter atau jumlah mata tunas per batang pada umur tanaman 6-7 BST (Khuluq dan Hamida, 2014). Jumlah batang berpengaruh terhadap jumlah mata tunas benih tebu. Dengan demikian diperlukan optimalisasi fase pertunasan agar didapatkan mata tunas yang maksimal pada Kebun Benih Datar. Taksasi dengan menggunakan persamaan regresi ini dipruntukkan bagi penangkaran benih system bagal.

Taksasi produksi penangkaran benih dengan metode SBP berbeda dengan sistem bagal. Satu bud set yang ditanam akan menghasilkan 8 batang per rumpun dengan tingkat multiplikasi rata-rata 80 mata sehingga dengan faktor koreksi $10 \%$ akan menghasilkan 70 tunas budset. Menurut Suhesti (2018) jumlah batang rata-rata per rumpun 7.91 dengan jumlah mata per batang rata-rata 10.15 sehingga multiplikasinya 86.17 dengan faktor koreksi 10 persen.

Hasil pengamatan pada umur tanaman 5 BST menunjukkan bahwa rata-rata jumlah batang per meter adalah 8,49 sehingga pendekatan taksasi produksi mata tunas rata-rata bila ditanam dengan system bagal adalah 681.888,6 mata per ha. Kebutuhan 
benih tebu pada KTG dengan asumsi, tanam 10 mata tunas/m , jumlah juring 1200 per ha (panjang juring $8 \mathrm{~m}$, PKP $1 \mathrm{~m}$, faktor koreksi lahan sawah 6\%) maka jumlah mata tunas yang dibutuhkan adalah 96.000 mata tunas per hektar. Dengan asumsi tersebut maka jumlah mata tunas dihasilkan pada penelitian tahun pertama (681.888,6 mata) dapat digunakan sebagai benih tebu KBI seluas 7.10 hektar.

Taksasi produksi benih yang ditanam dengan mentode SBP menghasilkan jumlah yang lebih banyak. Dengan jumlah batang rata-rata 8.49 per rumpun akan diperoleh benih sebanyak 2.256.000 mata tunas. Tiga kali lebih tinggi dari hasil penanaman benih metode bagal.

Luas areal tanam PG. Wringin Anom adalah 924 ha, bila dalam satu hektar terdiri dari 1200 juring dan dalam satu juring ditanami benih bagal 10 mata per $1 \mathrm{~m}$ juring (panjang juring $8 \mathrm{~m}$ ) maka dibutuhkan benih sebanyak 88.704.000 mata tunas. Sementara untuk PG. Pandji dengan luas tanam 124,0 ha dibutuhkan benih sebanyak 11.904 .000 mata tunas. Kebutuhan benih untuk PG. Wringin Anom dapat dipenuhi dari KBD seluas 39,32 ha (40 ha). Luasan tersebut diperoleh dengan asumsi per hektar lahan KBD terdiri dari 1175 juring (panjang juring $8 \mathrm{~m}$. PKP $1 \mathrm{~m}$ dan tara kebun 6\%). Dengan tingkat multiplikasi 80 maka per hektar lahan KBD akan menghasilkan 2.256.000 mata sehingga untuk luasan KTG 40 39.32) ha akan dapat memenuhi kebutuhan benih di KTG sebanyak 88.704.000 mata. Sementara itu kebutuhan benih KBD seluas 39.32 ha dapat diperolehdari 0.5 ha lahan KBI. Hal ini sesuai dengan pendapat Setyo (2916) bahwa setiap 1 ha KBI akan menghasilkan 35-40 ha KBD.

Wilayah kerja PG. Pandji dengan luas lahan tebu 124 hektar membutuhkan benih sebanyak 11.956.060 mata. Jumlah tersebut dapat dipenuhi dari 5.3 hektar lahan KBD.

Apabila kebun benih dikelola dengan system bagal maka lahan yang dibutuhkan lebih luas. Pada sistem bagal, 1 hektar lahan KBD hanya akan menghasilkan 7-10 hektar lahan KTG sementara untuk sistem SBP, 1 hektar lahan KBI akan menghasilkan 35-40 hektar KBD.

Pada tahun pertama telah dipilih beberapa petani calon penangkar benih yang pada Bulan Desember nanti akan meneria benih tebu hasil penelitian tahun pertama. Benih tersebut nantinya akan menjadi benih KBI yang akan menghasilkan benih KBD. Luaran dari penelitian tahun ketiga berupa benih KTG yang siap disebar kepada petani tebu giling yang ditanam dengan sistem bagal mata 2. Sebagai penelitian lanjutan, hasil berupa bobot timbang hasil panen, panjang batang hingga rendemen akan dibandingkan antara tebu yang ditana dengan menggunakan bibit asal-asalan dengan tebu yang menggunakan benih unggul bersertifikasi.

\section{KESIMPULAN}

Penyediaan benih tebu unggul bersertifikasi dengan metode SBP menghasilkan rata-rata jumlah batang per meter adalah 8,49 , taksasi produksi mata tunas apabila ditanam dengan metode bagal rata-rata adalah 681.888,6 mata per ha. Jumlah mata tunas ini dapat digunakan sebagai benih pada areal tanam 7.10 hektar KTG. Untuk luas wilayah tanam PG. Wringin Anom adalah 924,0 ha membutuhkan benih untuk KTG sebanyak 88.704.000 mata tunas. Dengan metode bagal dapat dipenuhi dari luas lahan KBD 130,09 ha. Sementara untuk Wilayah Kerja PG. Pandji dengan luas tanam 124 ha membutuhkan benih sebanyak 11.956.060 mata tunas, dapat dipenuhi dari 17,53 ha lahan KBD,

Dengan metode SBP kebutuhan benih dapat dipenuhi dari lahan KBD seluas 39,32 ha dengan jumlah benih 1.108.800 mata. Untuk PG. Pandji kebutuhan benih tersebut dapat dipenuhi dari lahan KBD seluas 5.3 ha dengan jumlah benih yang ditanam sebanyak 149.451 mata tunas. 


\section{REFERENSI}

Anonimous, 2008. "Penyediaan Bibit Tebu Berkualitas Melalui Kebun Berjenjang” Dalam http://pengawasbenihtanaman.blogspot.com/2008/05/penyediaan-bibit-tebuBerkualitas.html

Anonymous. 2014. Unit Usaha Pabrik Gula. www.ptpn11.co.id. Diakses pada tanggal 18 November 2016.

Balai Penelitian Tanaman Pemanis dan Serat. 2013. Pembibitan tebu. . Diakses tanggal 1 maret 2016.

Budi, S. 2016. Teknologi Pembuatan Bibit Tebu (Saccharum officinarum L.) Unggul Bersertifikat. Universita Muhammadiyah Malang Press.

Ditjenbun. 2017. Peningkatan produksi, produktivitas dan rendemen tanaman tebu untuk mencapai swasembada gula. Direktorat Jenderal Perkebunan, Jakarta.

Indrawanto, C., Purwono, Siswanto, M. Syakir, dan W. Rumini. 2010. Budi daya dan pascapanen tebu. ESKA Media. Jakarta. Hlm. 11.

Ismail, N.M., 2005. “Restrukturisasi Industri Gula Nasional.” Paper Ilmiah pada Seminar Gula Nasional, Jakarta.

Jain, R., S. Solomon, A.K. Shrivastava, and A. Chandra. 2010. Sugarcane bud chips: A promising seed material. Sugar Tech. 12(1): 67-69.

Khuluq, A.D. dan R. Hamida. 2014. Peningkatan produktivitas dan rendemen tebu melalui rekayasa fisiologis pertunasan. Perspektif 13(1):13-24.

Kusumaningrum, D. 2005. Sistem Penjadwalan Penanaman dan Pemanenan Tebu di PT. Gunung Madu Plantations. Departemen Teknologi Industri Pertanian. Fakultas Teknologi Pertanian. Institut Pertanian Bogor. Bogor.

Mulyono, D., 2003. "Analisis Ketersediaan Lahan untuk Mendukung Kapasitas Pabrik Gula." Laporan Akhir Proyek Unggulan Teknologi, Pusat Pengkajian dan Penerapan Teknologi Budidaya Pertanian, BPPT, Jakarta.

Natarajan, U.S. 2011. Tillering in SSI - Emergence, Factors Affecting, Constraints and Solutions. First National Seminar on Sugarcane Sustainable Initiative. p. 21-23.

Pentury, T., R.W. Matakupan, and L.J. Sinay. 2011. Aproksimasi distribusi waktu hidup yang akan datang. Jurnal Barekeng 5(1):47-51.

Pertanian, K., 2016. Outlook Tebu 2016, Pusat Data dan Sistem Informasi Pertanian Sekretariat Jenderal-Kementerian Pertanian 17.

[PUSLITBANGBUN]. 2010. Budidaya dan Pascapanen Tebu. Pusat Penelitian dan Pengembangan Perkebunan. Badan Penelitian dan Pengembangan Pertanian. 35 hlm. 
Suhesti, E., 2018. Upaya Peningkatan Kualitas Benih Tebu (Saccharum Officinarum L.) Melalui Metode Single Bud Planting Sebagai Bahan Tanam Kebun Benih. Universitas Brawijaya Malang.

Yuliardi, R. 2012. Bud Chip http://jccry.blogspot.com/2012/08/bud-chip.html. 